\title{
Coronary Microcirculation in Aortic Stenosis: Pathophysiology, Invasive Assessment, and Future Directions
}

\author{
Jo M. Zelis, ${ }^{1}$ Pim A. L. Tonino, ${ }^{1}$ Nico H. J. Pijls, ${ }^{1,2}$ Bernard De Bruyne, ${ }^{3,4}$ \\ Richard L. Kirkeeide, ${ }^{5}$ K. Lance Gould, ${ }^{5}$ and Nils P. Johnson ${ }^{5}{ }^{5}$ \\ ${ }^{1}$ Department of Cardiology, Catharina Hospital, Eindhoven, Netherlands \\ ${ }^{2}$ Department of Biomedical Engineering, Eindhoven University of Technology, Eindhoven, Netherlands \\ ${ }^{3}$ Department of Cardiology, Cardiovascular Center Aalst OLV Hospital, Aalst, Belgium \\ ${ }^{4}$ Department of Cardiology, Lausanne University Hospital, Lausanne, Switzerland \\ ${ }^{5}$ Weatherhead PET Center, Division of Cardiology, Department of Medicine, \\ McGovern Medical School at UTHealth and Memorial Hermann Hospital, Houston, Texas, USA
}

Correspondence should be addressed to Nils P. Johnson; nils.johnson@uth.tmc.edu

Received 8 May 2020; Revised 22 June 2020; Accepted 1 July 2020; Published 22 July 2020

Academic Editor: Joseph Dens

Copyright (c) 2020 Jo M. Zelis et al. This is an open access article distributed under the Creative Commons Attribution License, which permits unrestricted use, distribution, and reproduction in any medium, provided the original work is properly cited.

With the increasing prevalence of aortic stenosis (AS) due to a growing elderly population, a proper understanding of its physiology is paramount to guide therapy and define severity. A better understanding of the microvasculature in AS could improve clinical care by predicting left ventricular remodeling or anticipate the interplay between epicardial stenosis and myocardial dysfunction. In this review, we combine five decades of literature regarding microvascular, coronary, and aortic valve physiology with emerging insights from newly developed invasive tools for quantifying microcirculatory function. Furthermore, we describe the coupling between microcirculation and epicardial stenosis, which is currently under investigation in several randomized trials enrolling subjects with concomitant AS and coronary disease. To clarify the physiology explained previously, we present two instructive cases with invasive pressure measurements quantifying coexisting valve and coronary stenoses. Finally, we pose open clinical and research questions whose answers would further expand our knowledge of microvascular dysfunction in AS. These trials were registered with NCT03042104, NCT03094143, and NCT02436655.

\section{Introduction}

The seminal 4-group classification of coronary microvascular dysfunction proposed in 2007 placed aortic stenosis (AS) into a category with other myocardial diseases, both primary and secondary [1]. The importance of microcirculatory dysfunction due to AS has become even more clear given the confluence of increasing prevalence due to demographic changes [2] and of expanding treatment since the development of transcatheter aortic valve implantation (TAVI) [3]. Nevertheless, clinical observations enabled by refined diagnostic testing and less invasive treatment have, if anything, exposed unresolved physiologic questions regarding how we should understand, assess, and manage microvascular dysfunction in the patient with AS. This review addresses this practical need by summarizing the hemodynamic pathophysiology linking aortic stenosis and myocardial dysfunction, describing our invasive tools for quantifying microcirculatory function including its relationship with epicardial stenosis, and noting unresolved questions of clinical importance and how they might be answered. For clarity, we only focus on AS without coexisting myocardial pathology like amyloid or other infiltrative diseases.

\section{Supply versus Demand}

Uniquely among our organs, the heart must pump its own blood supply and cannot meaningfully augment oxygen extraction, implying that only increased supply can match increased need. Wall stress, contractility, and heart rate 
account for most myocardial oxygen consumption. The law of Laplace informs us that wall stress is directly proportional to pressure and to radius but inversely proportional to thickness. AS increases wall stress through elevated afterload, and, in response, the heart compensates through increased wall thickness. In other words, left ventricular (LV) hypertrophy offsets pressure overload to reduce wall stress and thereby oxygen requirements. However, LV hypertrophy brings its own disadvantages, namely, diastolic dysfunction, insufficient capillary density [4], and diffuse fibrosis [5].

As a semiquantitative and practical metric of coronary supply versus myocardial demand, a unitless index has been proposed using pressure measurements [6]. The area under the aortic (or, in situations of aortic stenosis, LV) curve during systole (the so-called systolic pressure time integral or SPTI) has been shown in animal models to have a very high and direct correlation with myocardial oxygen demand, even superior to the pressure-rate product [7]. The area between the aortic (or, in situations of epicardial disease, distal coronary) and LV pressure curves during diastole (the so-called diastolic pressure time integral or DPTI) provides a more sophisticated but similarly motivated metric than "coronary perfusion pressure" (difference in end-diastolic pressures between the aorta and LV) and resembles the supply to the myocardium. DPTI/SPTI balances supply and demand into a single unitless ratio, although this formulation ignores other factors such as arterial oxygen content and relative LV mass and wall tension [6]. Directional changes in an individual patient signal dynamic shifts in supply versus demand, while its unitless adjustment for absolute heart rate and blood pressure variation enables cross-sectional comparison among patients.

Although commonly considered as a single "myocardium," the subepicardial and subendocardial layers display distinct patterns of blood flow with differential sensitivity to pathology. On the one hand, the subepicardium faces generally low pressures from the pericardial space and thoracic cavity throughout the cardiac cycle, while, on the other hand, the subendocardium experiences generally low LV filling pressures during diastole that rise dramatically during systole. Even under normal conditions, the LV pressures during systole compress the subendocardium and redistribute flow to midmyocardial and subepicardial layers [8], a phenomenon explained by competing 'vascular waterfall' [9] and 'intramyocardial pump' [10] models. Consequently, after a 90-second coronary occlusion, the subepicardium reperfuses more quickly than the subendocardium [11]. Furthermore, during a wide range of pathologic perturbations, "the decrease in subendocardial and increase in subepicardial flow were often associated with normal or even elevated total coronary blood flows" [12], indicating that transmural maldistribution provides a unique guide for understanding many disease states. In animal models, a ratio below 0.8 has been demonstrated via microspheres to correlate with a reduction in subendocardial flow relative to the subepicardium; values $>0.8$ have been associated with intact and relatively homogeneous perfusion among myocardial layers [6].
To apply these principles of supply versus demand to aortic stenosis, consider the animal model in Figure 1 [12]. Under control conditions, no gradient exists between the LV and the aorta, DPTI and SPTI have similar areas under their respective curves (for a supply/demand ratio close to unity), and coronary perfusion displays a diastolic dominant pattern. As constriction begins using a band around the ascending aorta, left atrial pressure (a surrogate for LV filling pressures) rises, reducing DPTI supply at the same time that an elevated systolic pressure increases SPTI demand. Coronary flow becomes more dependent on flow during systole. With progressive constriction, these changes continue with falling DPTI supply (through a combination of increasing left atrial pressure and tachycardia), rising SPTI demand (as the band creates an ever worse supravalvular aortic stenosis), and emerging systolic-dominant coronary flow pattern. This fall in DPTI/SPTI preferentially affects the subendocardium; other animal studies have demonstrated a uniform endocardial/epicardial ratio of 0.97 and flows above $6 \mathrm{cc} / \mathrm{min} / \mathrm{g}$ under normal hyperemic conditions but an imbalanced ratio of 0.80 (less subendocardial flow) and fall in flow to below $4 \mathrm{cc} / \mathrm{min} / \mathrm{g}$ with valvular AS [13].

In many ways, Figure 1 provides a conceptual template for what happens in humans, albeit over a different time scale. Progressive AS increases SPTI, while rising LV filling pressures decrease DPTI, leading to a net reduction in the supply/demand (DPTI/SPTI) ratio. However, acute banding in animals does not have time to produce LV hypertrophy as in humans, which further increases the vulnerability of our subendocardium. Also, note that the tachycardia from acute banding in an animal model does not occur in humans with slowly progressive disease, although it represents an additional mechanism for reducing DPTI. For example, in a human cohort, with normal angiograms but critical aortic stenosis (4 subjects, mean gradient $93 \mathrm{mmHg}$, and aortic valve area $0.48 \mathrm{~cm}^{2}$ ), undergoing invasive hemodynamic study, average DPTI/SPTI of 0.34 with net lactate extraction at baseline 85 beats/minute fell with isoproterenol stress to DPTI/SPTI of 0.16 and switched to net lactate production at 113 beats/minute [14]. These observations could explain why patients can have angina from AS even with normal coronary arteries [15].

\section{Myocardial Resistance}

Unfortunately, our intuitive notion of "resistance" gained from daily life and basic electrical circuits often provides a suboptimal analogy for understanding myocardial behavior. As a result, much of the literature on "myocardial resistance" must be reviewed with caution or at least through the lens of a more sophisticated understanding. This section discusses key points relevant to understanding the concept as it applies to AS since the general topic goes beyond the scope of this review.

During baseline or resting conditions, myocardial flow remains relatively stable over a wide range of perfusion pressures [16] via a large number of homeostatic control mechanisms referred to in aggregate as "autoregulation." Consequently, basal myocardial resistance represents a 


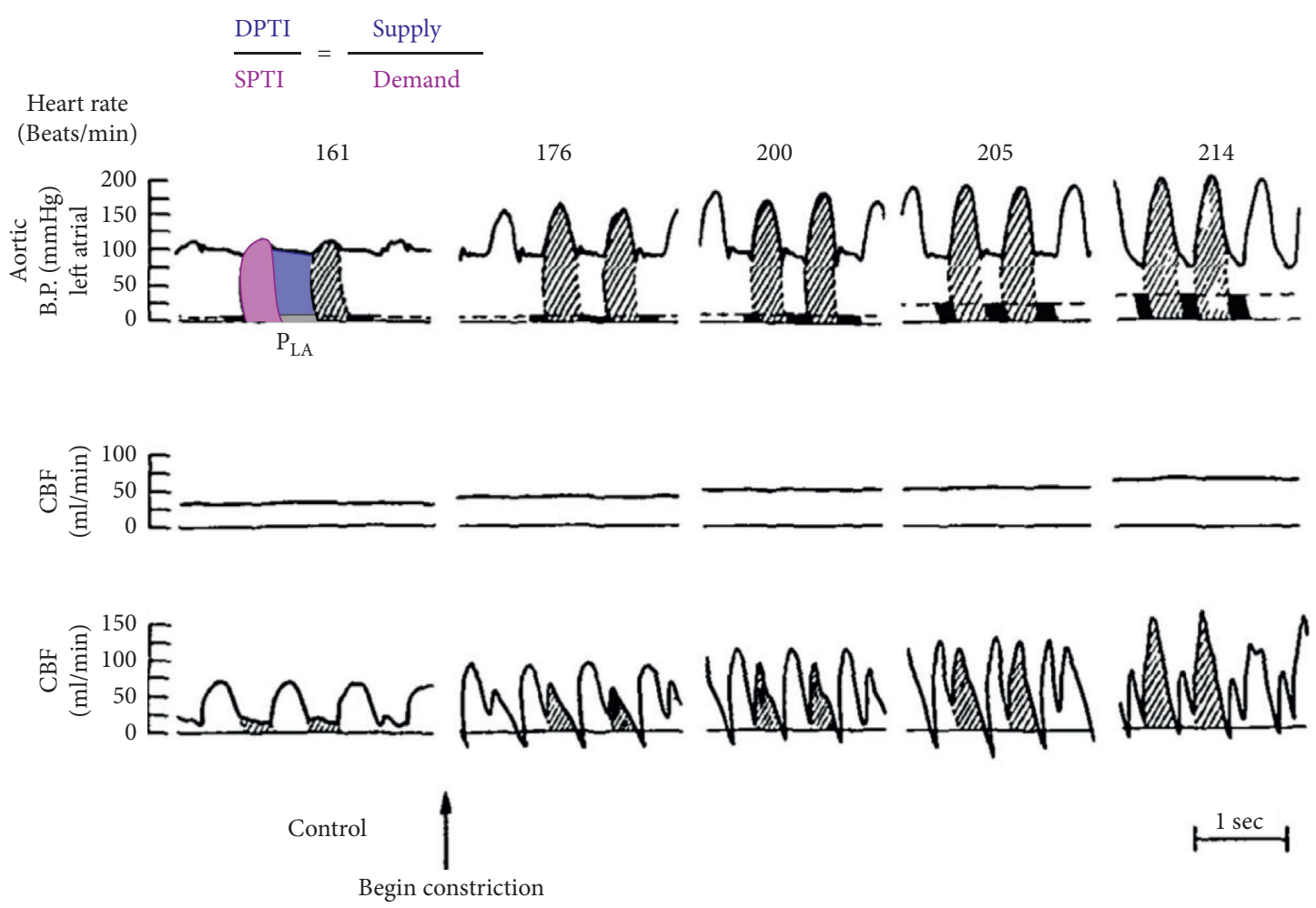

FIGURE 1: Animal aortic banding model that parallels the development of aortic valvular stenosis: at baseline, the systolic demand (shaded) and diastolic supply (not shaded) are well balanced when recording the aortic and left atrial pressures in this animal model of dynamic, supravalvular stenosis. With progressive banding demand rises (shaded area increases), supply falls (due to acute tachycardia in this animal model but also rising left atrial filling pressures marked as filled areas during diastole). Coronary blood flow (CBF, which corresponds to mean coronary blood flow) begins as diastolic dominant (unique to the normal heart) but concludes as systolic dominant (more typical of a peripheral organ bed) (reprinted from Figure 2 of a 1972 publication [12]).

dynamic phenomenon without unique value. Only under conditions of vasodilation does a largely linear relationship exist between perfusion pressure and flow, although somewhat curvilinear at very low perfusion pressures below the range of stable patients. The slope of this hyperemic relationship can be used to estimate resistance. However, in crucial distinction to an electrical resistor, coronary pressure does not fall to $0 \mathrm{mmHg}$ with complete occlusion of the epicardial artery. Depending on how it is measured, this residual pressure has been termed the coronary "wedge pressure" or "zero-flow pressure" or "back pressure." When accounting for venous and aortic pressures, the scaled wedge pressure quantifies relative maximum collateral blood flow [17].

Animal models of supravalvular aortic stenosis inform us about its effects on myocardial resistance. Compared to normal dogs, animals with LV hypertrophy after 8-10 months of aortic banding displayed a more shallow slope (less flow for the same coronary pressure) but also a higher wedge pressure [18] as depicted in Figure 2. More LV hypertrophy was associated with shallower slopes in that study, implying a dose-response relationship. Additionally, the wedge pressure was roughly twice as high in the setting of LV hypertrophy $(24 \mathrm{mmHg}$ versus $12 \mathrm{mmHg}$ ) and correlated with LV filling pressures (Pearson coefficient approximately
0.8 , indicating that $0.8^{2}=64 \%$ of the variation can be explained).

Several aspects add further complexity to this vasodilated relationship between flow and pressure. First, inotropic (dobutamine and exercise) and chronotropic stimulation can change the slope by about $20 \%$ in addition to increasing the wedge pressure $[19,20]$. This change in slope, corresponding to a higher resistance, might reflect the compressive effects of higher LV pressure and/or relatively more time spent in systole, indicating that a unique "minimum resistance" cannot be expected. Second, the myocardium displays capacitive and inductive effects necessitating the more general concept of impedance to account for phasic aspects in aortic pressure and flow. While many publications describe diastolic pressure/flow relationships [21], few account for these active effects that largely average out over the entire cardiac cycle. Third, the subepicardium and subendocardium display different pressure/flow relationships, generally with a similar slope but a lower zero-flow pressure in the subepicardium [22].

Before presenting existing resistance data in humans with AS, several points deserve to be mentioned. First, two main invasive techniques exist to measure coronary flow (Doppler flow velocity and bolus thermodilution), thereby introducing heterogeneity in the literature. Encouragingly, 

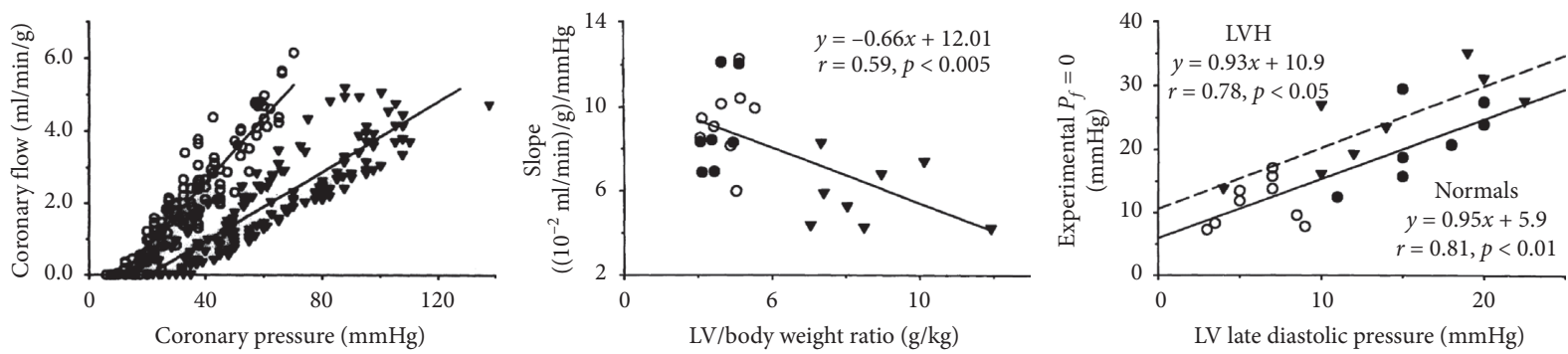

FIGURE 2: Myocardial resistance in an animal model of aortic stenosis: at about 2 months of age, a $20-25$ mmHg peak systolic gradient is created in dogs who were then studied at 10-14 months of age and compared with normal animals. During intravenous adenosine infusion, coronary flow is measured as a function of coronary pressure with progressive coronary constriction. Open circles represent normal dogs, and closed triangles represent those with supravalvular aortic stenosis. The flow versus pressure relationship (left) shifts to the right and rotates clockwise when moving from normal to aortic stenosis. Its slope relates inversely to the amount of left ventricular hypertrophy (middle), indicating a dose-response relationship. Its intercept correlates directly with left ventricular filling pressures (right). In these ways, the decrease in slope corresponds to an increase in myocardial resistance and the change in intercept to a rising zero-flow pressure due to higher LV filling pressures (reprinted from Figures 1-3 of a 1993 publication [19]).

vasodilatory hyperemia to enable either technique appears safe in patients with severe AS based on 40 reports from 1820 patients over 3 decades as summarized in Table 1. Second, techniques using bolus thermodilution [62] and Doppler flow velocity [63] have demonstrated an important bias when quantifying resistance by neglecting wedge pressure assessment in situations when the wedge pressure is elevated. Since most patients with severe AS undergoing TAVI or surgical aortic valve replacement (SAVR) will have at least a moderate elevation in LV filling pressure, which tracks with wedge pressure $[18,19]$, resistance measurements without this correction should be viewed skeptically. Third, to our knowledge, no study has yet distinguished between changes in wedge pressure versus slope when studying myocardial pressure/flow relationships in human AS. However, continuous thermodilution with the added technique of proximal balloon inflation can create an almost continuous flow versus pressure curve that allows both parameters to be estimated [64].

Table 2 presents a summary of the literature that has reported resistance assessment in humans with AS, both before and after TAVI. Data from 7 studies with a total of 174 vessels either compared resistance between normal patients and those with severe AS and/or serial resistance measurements in the same patients with severe AS before and after TAVI. While limited by modest sample sizes, two different techniques for measuring resistance, and lack of separate slope and zero-flow pressures (apart from 1 study that did measure wedge pressure explicitly), the data suggest two key points in keeping with the animal work described previously: myocardial resistance in AS exceeds that in normal subjects, and resistance falls after TAVI, both acutely and in the longer-term.

\section{Epicardial Stenosis}

While severe AS by itself can be sufficient to explain symptoms of heart failure or angina, due to a supplydemand mismatch discussed above, epicardial coronary disease of angiographic significance can be seen in $40 \%$ to
$75 \%$ of these patients [65]. Due to near-ubiquitous coronary angiography before TAVI, either invasively or via computed tomography, frequently identified epicardial lesions pose an unresolved treatment dilemma. Rarely is a stenosis so proximal and critical as to require percutaneous coronary intervention (PCI) in order to perform TAVI safely. In most situations, a stenosis could be treated either before or after TAVI with tradeoffs among benefit (usually symptoms resolve with TAVI alone, and the impact of PCI on spontaneous myocardial infarction remains unclear in this older population with severe AS), ease of coronary access (more difficult after TAVI), periprocedural risk (potentially, complications are less well-tolerated with severe AS), and antiplatelet therapy (less flexible after PCI). Table 3 summarizes ongoing randomized trials in this area. In the interim, observational data using fractional flow reserve (FFR) suggested improved outcomes, defined as a composite of death, myocardial infarction, and stroke, versus angiographic selection, mainly through the avoidance of procedural complications in lesions lacking a large hyperemic pressure gradient [66].

Superimposing a coronary stenosis on severe AS exacerbates the supply/demand mismatch. A fixed epicardial stenosis produces a pressure loss that increases with flow but has separate contributions from viscous (friction, linear) and separation (expansion, quadratic) components. Figure 3 superimposes this net stenosis pressure/flow relationship on the description of myocardial performance during vasodilation. The intersection of the stenosis curve and the myocardial load line represents the observations at hyperemia with corresponding FFR and coronary flow reserve (CFR) values [69]. During resting conditions, coronary flow is controlled by autoregulation and does not change, translating into stable nonhyperemic pressure ratios over time as demonstrated in the literature summarized in Table 4 . While constancy can be comforting, it overlooks that most patients remain asymptomatic at rest, and thus, only a hyperemic assessment could link with exertional symptoms, acknowledging that dedicated studies 
TABLE 1: Literature review of vasodilator stress agents in severe aortic stenosis.

\begin{tabular}{|c|c|c|c|c|c|}
\hline Authors & Citation & $N$ & Drug & Technique & Safety issues \\
\hline Roy et al. [23] & Nucl Med Commun 1998; 19: 789 & 12 & Dipy & SPECT & No \\
\hline Carpeggiani et al. [24] & J CV Med 2008; 9: 893 & 15 & Dipy & PET & No \\
\hline Liu et al. [25] & Sci Rep 2019; 9: 12443 & 15 & Dipy & SPECT & No \\
\hline Burwash et al. [26] & Heart 2008; 94: 1627 & 20 & Dipy & PET & No but 16 excluded \\
\hline Rajappan et al. [27] & Circulation 2002; 105: 470 & 20 & Dipy & PET & No \\
\hline Nemes et al. [28] & Herz 2002; 27: 780 & 21 & Dipy & TTE & No \\
\hline Baroni et al. [29] & Heart 1996; 75: 492 & 25 & Dipy & TTE & No \\
\hline Huikuri et al. [30] & AJC 1987; 59: 336 & 27 & Dipy & SPECT & 2 hypotension \\
\hline Demirkol et al. [31] & Cardiology 2002; 97: 37 & 30 & Dipy & SPECT & No \\
\hline Nemes et al. [32] & $\begin{array}{c}\text { Clin Physiol Funct Imaging 2009; 29,: } \\
447\end{array}$ & 49 & Dipy & TTE & No \\
\hline Avakian et al. [33] & IJC 2001; 81: 21 & 110 & Dipy & SPECT & No \\
\hline Camuglia et al. [34] & JACC 2014; 63: 1808 & 10 & IC adeno & $\begin{array}{l}\text { Doppler } \\
\text { wire }\end{array}$ & No \\
\hline Vendrik et al. [35] & JAHA 2020; 9:e015133 & 13 & IC adeno & FFR & No \\
\hline Wiegerinck et al. [36] & Circ CV Int 2015; 8:e02443 & 27 & IC adeno & Combo & No \\
\hline Ahmad et al. [37] & JACC CV Int 2018; 11: 2019 & 28 & IC adeno & FFR & No \\
\hline Scarsini et al. [38] & EuroIntervention 2018; 13: 1512 & 66 & IC adeno & FFR & No \\
\hline Di Gioia et al. [39] & AJC 2016; 117: 1511 & 106 & IC adeno & FFR & No \\
\hline Scarsini et al. [38] & J Cardiovasc Transl Res 2019; 12: 539 & 82 & $\begin{array}{l}\text { IC/IV } \\
\text { adeno }\end{array}$ & FFR & No \\
\hline Stähli et al. [40] & Cardiology 2012; 123: 234 & 4 & IV adeno & FFR & No \\
\hline Stundl et al. [41] & Clin Res Cardiol 2019; 109 & 13 & IV adeno & FFR & No \\
\hline Lumley et al. [42] & JACC 2016; 68: 688 & 19 & IV adeno & FFR & No \\
\hline Burgstahler et al. [43] & IJ CV Img 2008; 24: 195 & 20 & IV adeno & CMR & No \\
\hline $\begin{array}{l}\text { Hildick-Smith and Shapiro } \\
\text { [44] }\end{array}$ & JACC 2000; 36: 1889 & 27 & IV adeno & TTE & 1 "tolerated poorly" \\
\hline Mahmod et al. [45] & JCMR 2014; 16: 29 & 28 & IV adeno & CMR & No \\
\hline Samuels et al. [46] & JACC 1995; 25: 99 & 35 & IV adeno & SPECT & 2 hypotension, 2 AV block \\
\hline Gutiérrez-Barrios et al. [47] & Int J Cardiol 2017; 236: 370 & 36 & IV adeno & FFR & No \\
\hline Stoller et al. [48] & EuroIntervention 2018; 14: 166 & 40 & IV adeno & FFR & No \\
\hline Takemoto et al. [49] & JASE 2014; 27: 200 & 41 & IV adeno & TTE/FFR & No \\
\hline Patsilinakos et al. [50] & Angiology 1999; 50: 309 & 50 & IV adeno & TTE/SPECT & No \\
\hline Stanojevic et al. [51] & J Inv Card 2016; 28: 357 & 72 & IV adeno & FFR & No \\
\hline Patsilinakos et al. [52] & JNC 2004; 11: 20 & 75 & IV adeno & SPECT & 9 AV block \\
\hline Yamanaka et al. [53] & JACC CV Int 2018; 11: 2032 & 95 & IV adeno & FFR/SPECT & $\begin{array}{l}1 \mathrm{AV} \text { block, } 10 \% \\
\mathrm{SBP}<40 \mathrm{mmHg}\end{array}$ \\
\hline Ahn et al. [54] & JACC 2016; 67: 1412 & 117 & IV adeno & CMR & No \\
\hline Banovic et al. [55] & Echo 2014; 31: 428 & 127 & IV adeno & TTE & No \\
\hline Singh et al. [56] & EHJ 2017; 38: 1222 & 174 & IV adeno & CMR & No \\
\hline Nishi et al. [57] & Coron Artery Dis 2018; 29: 223 & 9 & Mixed & FFR & No \\
\hline Arashi et al. [58] & Cardiovasc Interv Ther 2019; 34: 269 & 13 & Mixed & FFR & No \\
\hline Hussain et al. [59] & JNC 2017; 24: 1200 & 95 & Mixed & SPECT & No \\
\hline Banovic et al. [60] & Coron Artery Dis 2020; 31: 166-73 & 4 & NR & FFR & No \\
\hline Cremer et al. [61] & JNC 2014; 21: 1001 & 50 & Rega & PET & 2 hypotension \\
\hline
\end{tabular}

$\mathrm{AV}=$ atrioventricular, adeno $=$ adenosine, $\mathrm{CMR}=$ cardiac magnetic resonance, dipy $=$ dipyridamole, $\mathrm{FFR}=$ fractional flow reserve, $\mathrm{IC}=$ intracoronary, $\mathrm{IV}=$ intravenous, $N=$ number of subjects, $\mathrm{NR}=$ not reported, $\mathrm{PET}=$ positron emission tomography, rega = regadenoson, $\mathrm{SBP}=$ systolic blood pressure, SPECT $=$ single-photon emission computed tomography, and TTE $=$ transthoracic echocardiography.

in AS are currently lacking and would be confounded by valvular symptoms.

Based on the discussion of myocardial resistance in the prior section, the existing data support an increase in hyperemic flow after TAVI due to a change in the myocardial load line. This change occurs both via a reduction in wedge pressure, largely mediated by its direct correlation with LV filling pressures $[18,19]$ that fall after AS has been treated, and a counterclockwise rotation from increasing slope [18]. However, the existence, time course, and relative magnitude of these changes after TAVI in humans have not been demonstrated.

In contrast to inferences regarding the mechanisms in Figure 3, the secondary effect on the intersection of a fixed stenosis curve but dynamic myocardial load line can be seen more directly from observations summarized in Table 4 from 12 publications and about 350 lesions [68]. Overall resting flow may decrease slightly in the first year as expected from reduced myocardial demand, although the data imply that this effect remains modest and has essentially no impact 
TABLE 2: Literature review of hyperemic myocardial resistance with severe aortic stenosis.

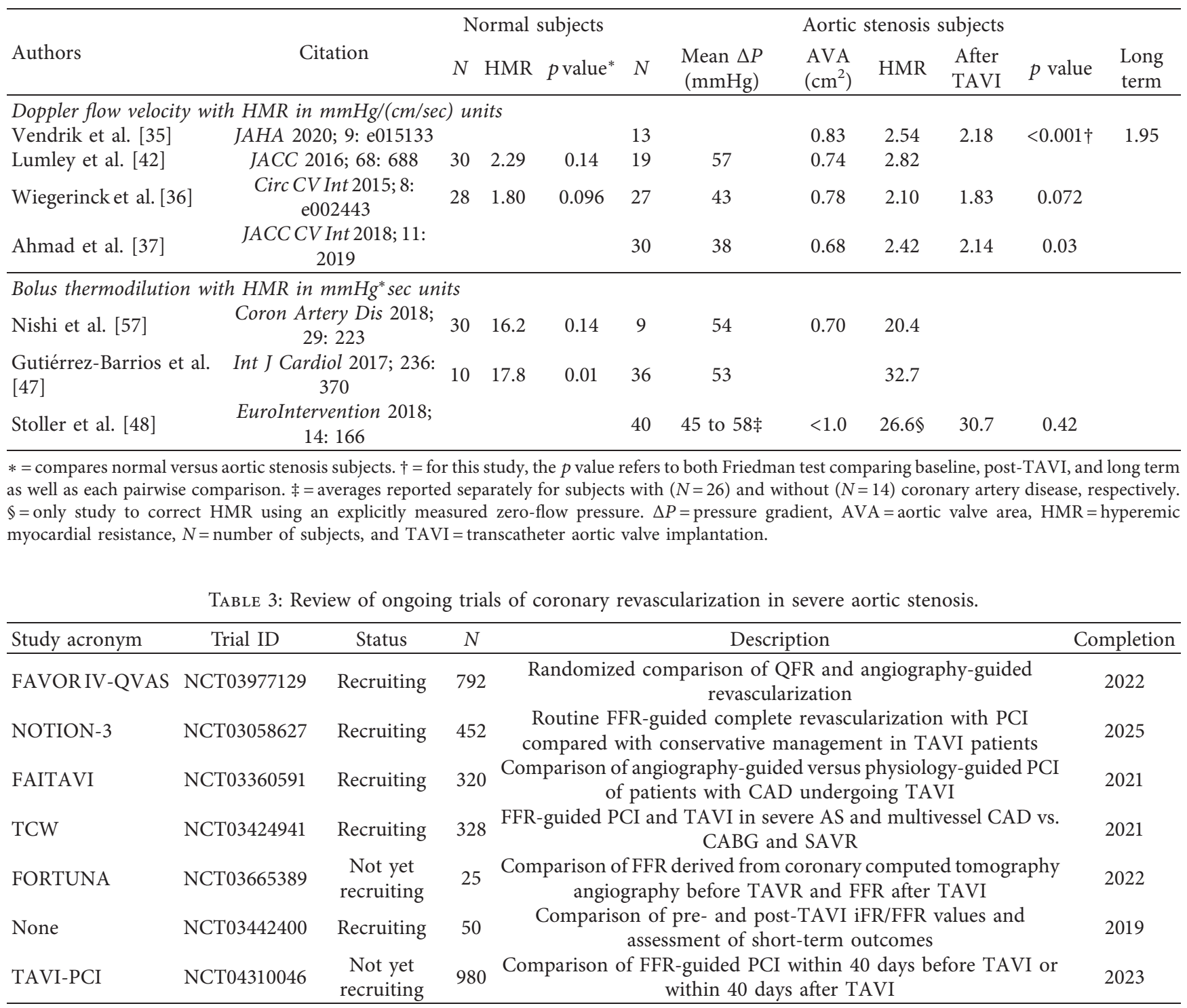

on nonhyperemic pressure ratios. More clearly suggested by the data is an acute increase in peak hyperemic flow with concomitantly higher CFR and lower FFR. However, these studies were small or modestly sized, used a variety of measurement techniques for flow, and did not stratify changes based on properties of the myocardial load line or stenosis curve. In these studies, coronary hyperemia was appropriately induced by pharmacologic stress in order to focus on fixed epicardial disease emphasized by pure vasodilation (and appropriate for revascularization) as opposed to exercise stress that includes vasoconstriction whose treatment is fundamentally medical.

The proposed model in Figure 3 neglects the important physiologic differences between the subepicardium and the subendocardium. Thus, Figure 4 depicts two separate curves relating pressure and flow in distinct layers of the myocardial wall. Under conditions of vasodilation, the higher LV pressures reduce flow in the subendocardium, which becomes further exacerbated as diastolic perfusion time decreases with exercise. While not possible to measure different FFR values in various layers of the myocardium, Figure 4 nevertheless provides an explanatory framework for understanding the differential impact of epicardial coronary lesions on the microvasculature.

Figure 5 provides a clinical example of applying the DPTI/SPTI concept to individual data from an 82-year-old man with exertional dyspnea and a severe in-stent lesion in the right coronary artery but also a mean aortic valve gradient of $51 \mathrm{mmHg}$. In this case, an already reduced DPTI/ SPTI became radically diminished as a result of diastolic pressure loss from the epicardial lesion. During hyperemia, the FFR reached 0.54 , and the DPTI/SPTI fell to 0.16 , the same as the average value in the previously mentioned study in which patients with critical AS switched to lactate production [14]. While removing the coronary stenosis might have increased the DPTI/SPTI to 0.66 , only treating both AS and the coronary lesion would produce a balanced DPTI/ SPTI of 0.95 . As noted earlier, we do not have randomized 


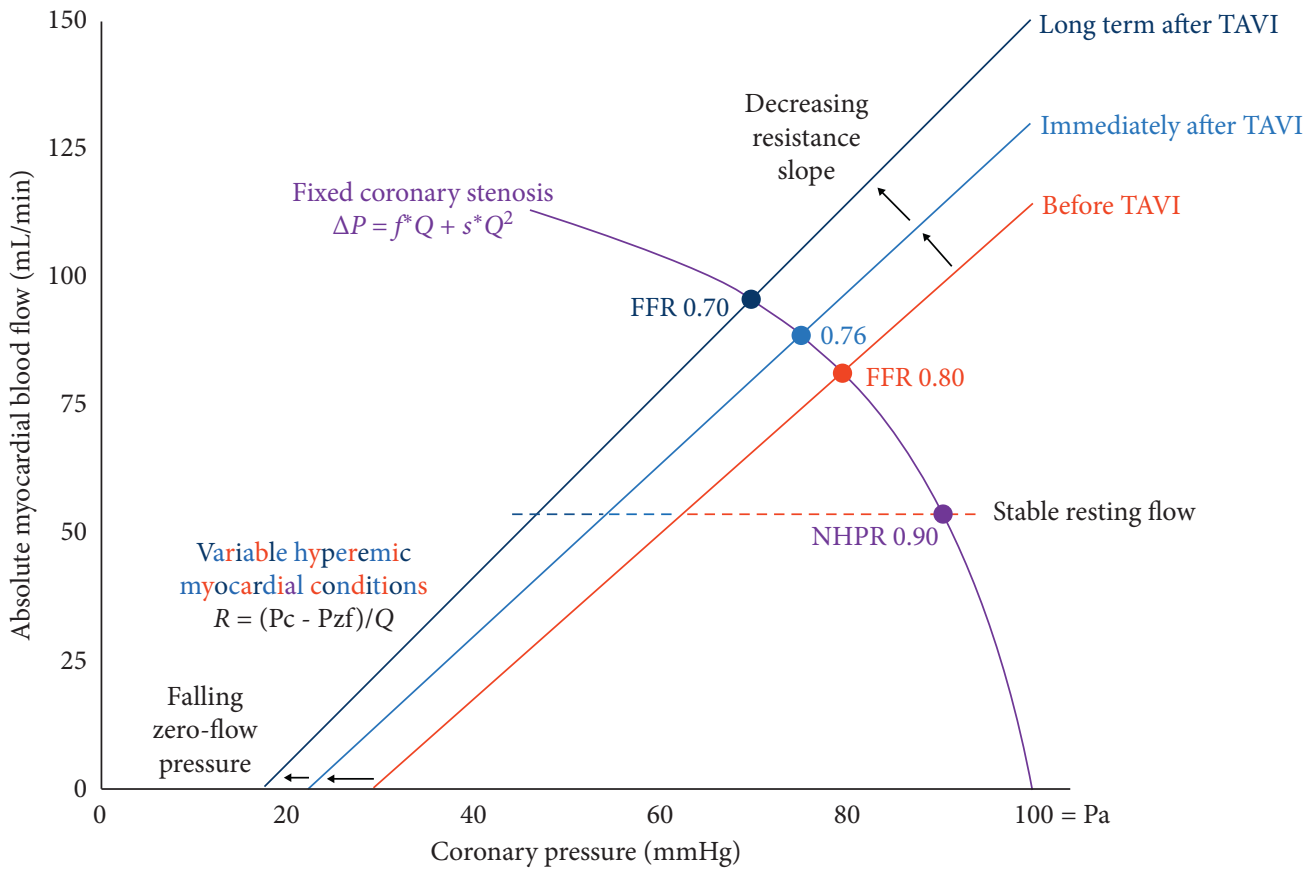

FIgURE 3: Myocardial flow versus coronary pressure relationships: during hyperemia, a linear relationship exists between absolute myocardial blood flow and coronary pressure (basically equal to aortic pressure in the absence of a stenosis). This so-called myocardial "load line" has both slope (how much extra flow for an increase in driving pressure) and offset (often referred to as the zero-flow or wedge pressure depending on how it is measured). The slope of the myocardial load line corresponds to the myocardial resistance which can be calculated through the formula $R=(\mathrm{Pc}-\mathrm{Pzf}) / Q$, where $R$ is the resistance, $\mathrm{Pc}$ is the coronary pressure, Pzf is the zero-flow, and $Q$ is the flow. Under resting conditions (horizontal dashed line), the myocardium is capable of autoregulation to maintain a roughly constant flow over a wide range of perfusion pressures reflected by a constant nonhyperemic pressure ratio (NHPR). A fixed coronary stenosis produces both friction (" $f$ ") and separation (" $s ")$ components to net pressure loss as can be deduced from the well-known coronary stenosis formula $\Delta \mathrm{P}=f * Q+s * Q^{2}$, where $P$ is the pressure loss in $\mathrm{mmHg}$ and $\mathrm{Q}$ is the coronary flow in $\mathrm{mL} / \mathrm{min}$ [67]. Its intersection with the myocardial load line represents the observations of FFR and maximum flow at peak hyperemia. Potential changes in the myocardial load line have been shown before versus after transcatheter aortic valve implantation (TAVI), although the relative magnitude and time course of a left shift (due to a fall in left ventricular filling pressures) and counterclockwise rotation (corresponding to more flow for the same driving pressure) have not yet been quantified (reprinted from the figure of recent 2020 editorial [68]).

trials demonstrating clinical advantages to treating coexisting coronary disease, but hemodynamically severe and focal lesions supplying large amounts of myocardium, as in this case, seem reasonable candidates for PCI based on using FFR in patients without AS.

\section{Unanswered Questions}

A review not only provides an opportunity to look backward and synthesize existing knowledge but also offers the possibility to identify gaps that remain and how they might be filled in the future. On a basic level, measuring in humans the changes seen in animal models [18] regarding myocardial load lines versus zero-flow pressure would provide us with a better appreciation for acute versus chronic benefits of TAVI. Perhaps, the immediate procedural impact of TAVI on the myocardium predominately affects zero-flow pressure (through a reduction in LV filling pressures as seen in animal work [18]), whereas chronic remodeling over months mainly changes the slope of the myocardial load line (through a regression in LV hypertrophy as seen in animal models [20]). Continuous thermodilution with the added technique of proximal balloon inflation provides perhaps the most comprehensive yet practical examination in order to separate and quantify these effects in actual patients undergoing treatment [64].

Apart from a confirmation of translational animal physiology and conceptual insight, what clinical advantages might come from such data? Currently, we do not understand when to treat mixed coronary disease and AS, and in some cases, FFR values fall after TAVI, particularly when previously in the 0.75 to 0.85 range [68]. If we understood the degree and time course of myocardial changes after TAVI, then we could better predict which coronary lesions might take on added importance and benefit from revascularization versus those that would remain hemodynamically modest, even after longer-term remodeling. Additionally, some patients with valvular cardiomyopathy recover LV function after TAVI, whereas others remain depressed. Does the slope of the myocardial load line predict this potential reversibility? If yes, then it would permit better patient selection in order to optimize the TAVI risk/benefit. Finally, the changes in myocardial resistance should be expected to be linked to pretreatment severity of the AS as well as the hemodynamic efficacy of the TAVI device. Because myocardial resistance is 


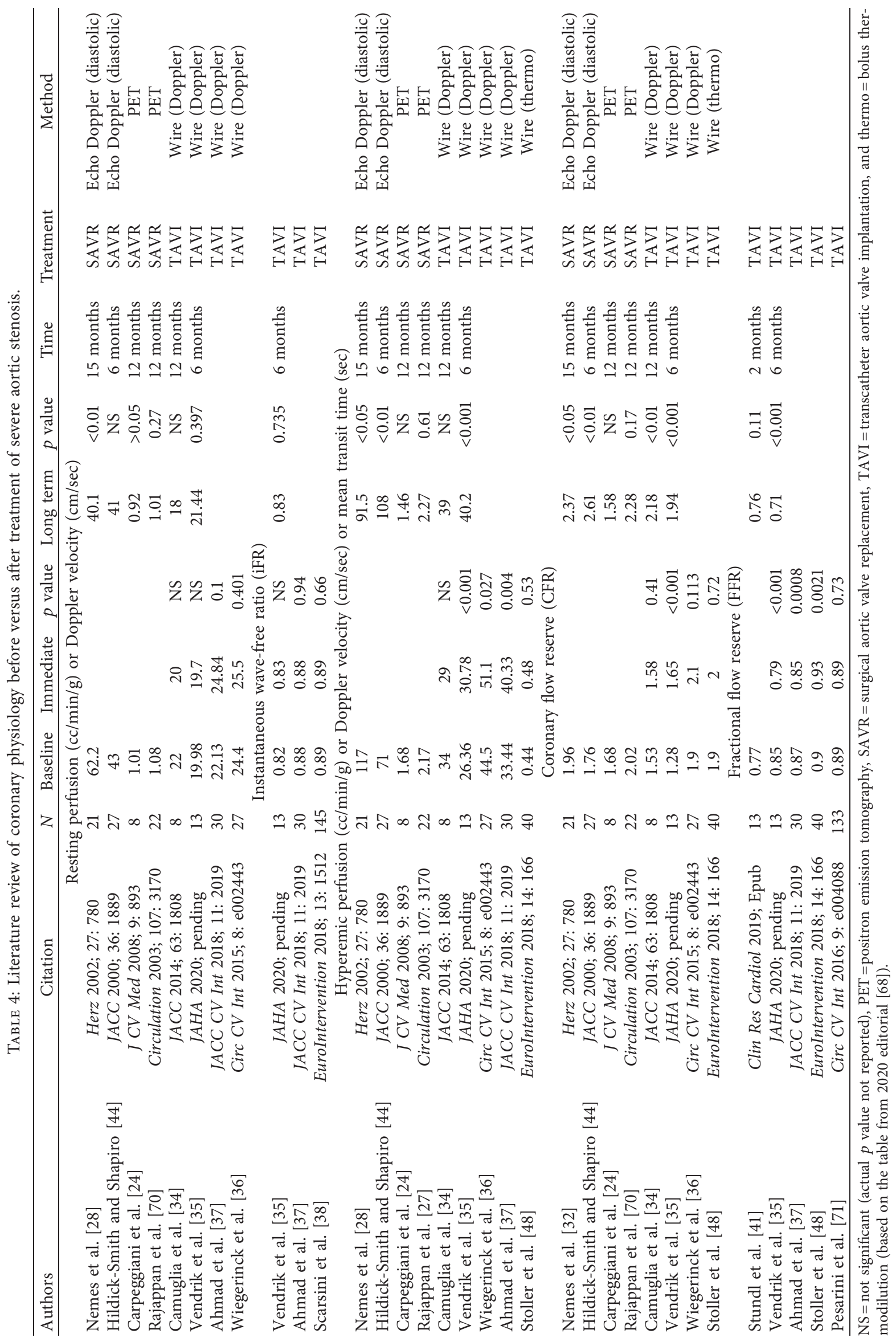



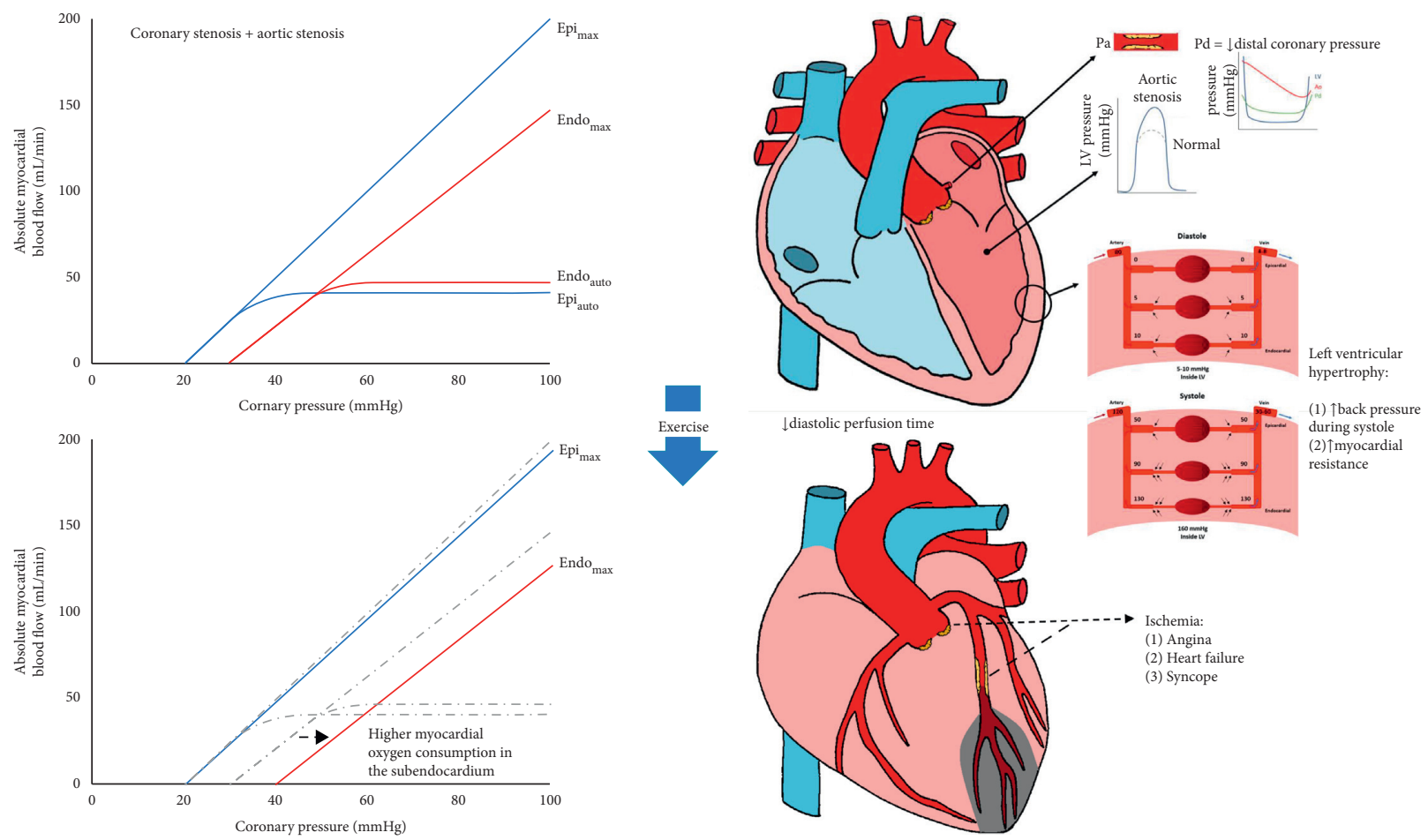

FIgURE 4: Transmural impact of aortic stenosis with coronary disease: reduced flow from aortic stenosis and coronary stenosis does not affect all layers of the myocardium equally. Under baseline conditions, autoregulation ("auto" subscript) maintains a relatively stable flow for most perfusion pressures. Vasodilation ("max" subscript) produces the net hyperemic myocardial load line from Figure 3 that is made up of a lower offset in the subepicardium (Epi) than the subendocardium (Endo), with potentially different slopes as well. Exercise reduces diastolic perfusion time and increases left ventricular pressures, preferentially affecting the subendocardium both through tachycardia and also increased oxygen consumption. The resulting hypoperfusion can produce the classic symptoms of valvular stenosis.
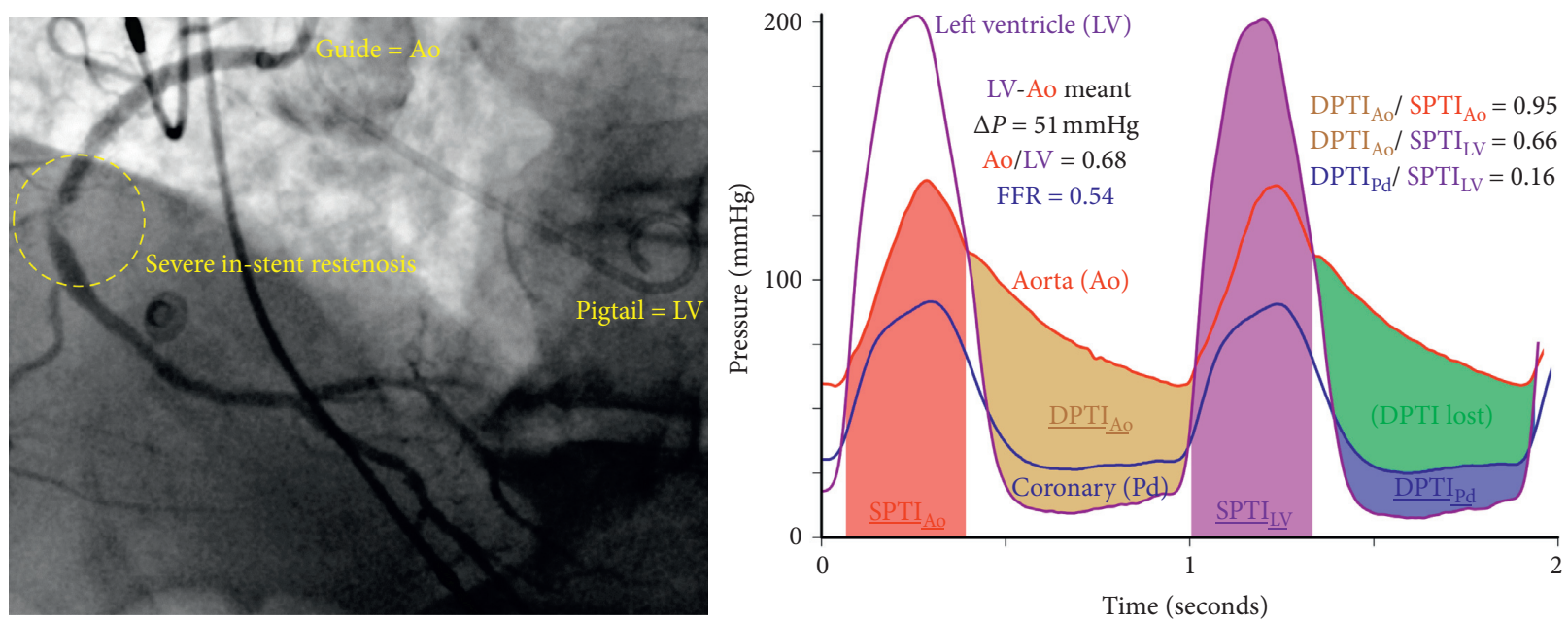

FIGURE 5: Clinical case of simultaneous aortic and coronary stenosis assessment: as detailed in the text, this 82-year-old man with exertional dyspnea underwent coronary evaluation before transcatheter aortic valve implantation. Three pressures were measured simultaneously: aortic (via the guide catheter), coronary (via a distal pressure wire), and left ventricular (via a pigtail catheter). Intravenous papaverine induced coronary hyperemia with a fractional flow reserve (FFR) of 0.54 . Both the severe aortic stenosis (baseline mean gradient $51 \mathrm{mmHg}$ ) and the severe in-stent coronary lesion imbalance myocardial demand (systolic pressure time integral, or SPTI) and diastolic coronary supply (diastolic pressure time integral, or DPTI). This figure allows for a visual understanding of the additive effects of the tandem aortic valve and coronary stenosis.

inherently a hyperemic concept, do baseline parameters such as the resting valve gradient or aortic valve area perform worse than hyperemic parameters such as the stress aortic valve index (SAVI) [72]? In that case, it would argue against relying solely on resting measurements when selecting patients for TAVI. 

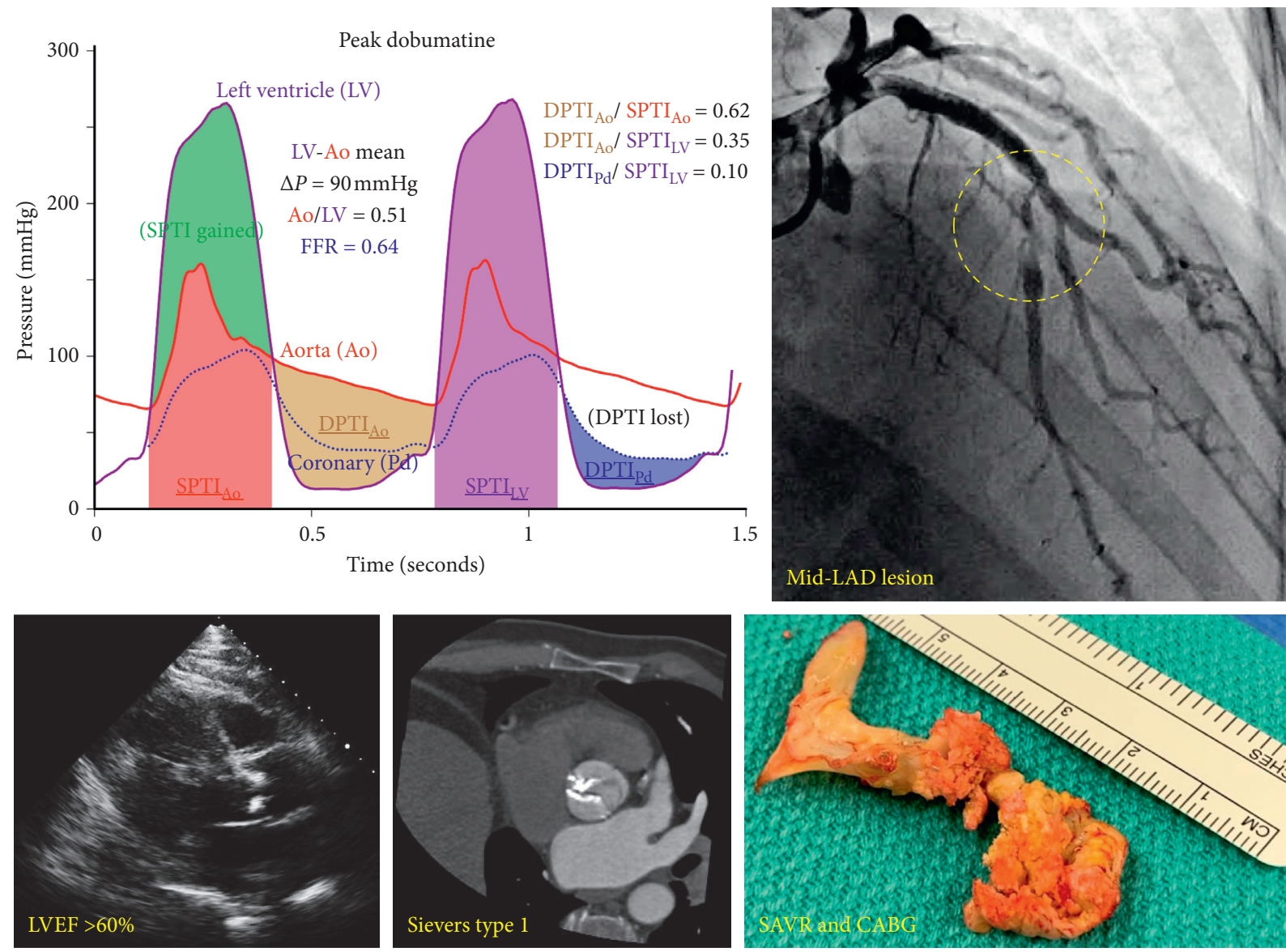

FIgURE 6: Clinical case of asymptomatic but severe stenosis: as detailed in the text, this 55-year-old asymptomatic man was referred for an incidental heart murmur on routine physical examination. A treadmill exercise test showed good functional capacity with no symptoms or abnormal responses, and echocardiography found normal ejection fraction. However, his bicuspid aortic valve had moderate-to-severe stenosis at baseline, rising to a mean gradient of $90 \mathrm{mmHg}$ during intravenous dobutamine stress. Furthermore, his left anterior descending (LAD) coronary artery had an angiographically moderate-to-severe stenosis and fractional flow reserve (FFR) of 0.64 during intravenous adenosine infusion. When superimposing these curves (the distal coronary pressure tracing has been time-scaled to match the aortic pressure tracing), myocardial oxygen demand (systolic pressure time integral, or SPTI) greatly exceeds diastolic coronary supply (diastolic pressure time integral, or DPTI) due to increased SPTI from aortic stenosis and decreased DPTI due to coronary stenosis. Despite normal left ventricular function and a lack of symptoms, the patient underwent surgical aortic valve replacement (SAVR) and concomitant coronary artery bypass grafting $(\mathrm{CABG})$ for extremely abnormal hemodynamics.

As a final sign of our yet incomplete knowledge of the coronary microcirculation in aortic stenosis, a clinical case is considered in Figure 6. This 55-year-old man was referred by his internist for an incidental murmur noted during a routine physical examination that was otherwise unremarkable. In daily life, he had no symptoms and performed 9:32 minutes of a standard Bruce treadmill protocol. Blood pressure, heart rate, and heart rhythm response were normal during the graded exercise; he denied angina and stopped due to leg fatigue. Echocardiography revealed normal LV function with an ejection fraction over $60 \%$. Therefore, we have an asymptomatic patient with no evidence of subclinical cardiomyopathy.

However, extensive workup revealed a calcified bicuspid aortic valve with moderate-to-severe stenosis at baseline, rising to a mean gradient of $90 \mathrm{mmHg}$ during intravenous dobutamine infusion with a SAVI of 0.51 (indicating that peak valvular flow is reduced by the stenotic valve to $51 \%$ of maximum). A calcified mid-LAD stenosis had an FFR of 0.64 during intravenous adenosine with a focal pressure jump. An analysis of DPTI/SPTI (although not direct in this case since the valve and coronary stenoses were interrogated sequentially using different pharmacologic agents) showed a potential drop to 0.10 during peak stress, entering the region that has been associated with net lactate production in a small human study [14]. Therefore, we have coexisting and severe aortic and coronary stenoses confirmed by objective hemodynamic data.

Should we understand this case as a profound challenge to the relevance of hemodynamic physiology reviewed in this article? Or does it indicate that patient symptoms (or their lack) as well as standard noninvasive testing often tell us at most a modest amount regarding physiologic severity, thereby necessitating routine quantification? While awaiting the results of ongoing randomized controlled trials of TAVI in severe yet asymptomatic AS (clinicaltrials.gov, NCT03042104, NCT03094143, and NCT02436655), what 
should we currently do with such patients who nevertheless exhibit extreme hemodynamic derangements? Can we expect that the reduction in sudden death seen in a small trial of SAVR for asymptomatic yet severe AS (mean gradient $63 \mathrm{mmHg}$ ) [73] will be confirmed in larger, ongoing trials? While these vital questions cannot be answered definitively at this moment, they serve as humble reminders regarding the profound capacity of the human coronary microcirculation in some patients to withstand a severe assault on multiple fronts.

\section{Conflicts of Interest}

JMZ reports no support or industry relationships. PALT, NHJP, RLK, KLG, and NPJ have a patent pending on diagnostic methods for quantifying aortic stenosis and TAVI physiology. PALT reports no additional support or industry relationships. NHPJ receives institutional grant support from Abbott, serves as a consultant for Abbott and Opsens, and possesses equity in Philips, GE, ASML, and Heartflow. $\mathrm{BDB}$ has received institutional research grants and consulting fees from Abbott Vascular (formerly St. Jude Medical), Boston Scientific, and Opsens. BDB, RLK, KLG, and NPJ have a patent pending on correcting pressure signals from fluid-filled catheters. RLK reports no additional support or industry relationships. KLG is the $510(\mathrm{k})$ applicant for CFR Quant (K113754) and HeartSee (K143664 and K171303), software packages for cardiac positron emission tomography image processing, analysis, and absolute flow quantification. NPJ receives internal funding from the Weatherhead PET Center for Preventing and Reversing Atherosclerosis, has an institutional licensing and consulting agreement with Boston Scientific for the smart minimum FFR algorithm (commercialized under 510(k) K191008), and has received significant institutional research support from St. Jude Medical (CONTRAST, NCT02184117) and Philips Volcano Corporation (DEFINEFLOW, NCT02328820), studies using intracoronary pressure and flow sensors.

\section{References}

[1] P. G. Camici and F. Crea, "Coronary microvascular dysfunction," New England Journal of Medicine, vol. 356, no. 8, pp. 830-840, 2007.

[2] A. P. Durko, R. L. Osnabrugge, N. M. Van Mieghem et al., "Annual number of candidates for transcatheter aortic valve implantation per country: current estimates and future projections," European Heart Journal, vol. 39, no. 28, pp. 2635-2642, 2018.

[3] H. R. Andersen, L. L. Knudsen, and J. M. Hasenkam, "Transluminal implantation of artificial heart valves. description of a new expandable aortic valve and initial results with implantation by catheter technique in closed chest pigs," European Heart Journal, vol. 13, no. 5, pp. 704-708, 1992.

[4] E. A. Breisch, S. R. Houser, R. A. Carey, J. F. Spann, and A. A. Bove, "Myocardial blood flow and capillary density in chronic pressure overload of the feline left ventricle," Cardiovascular Research, vol. 14, no. 8, pp. 469-475, 1980.

[5] B. Schwartzkopff, H. Frenzel, J. Diekerhoff et al., "Morphometric investigation of human myocardium in arterial hypertension and valvular aortic stenosis," European Heart Journal, vol. 13, no. suppl D, pp. 17-23, 1992.

[6] J. I. E. Hoffman and G. D. Buckberg, "The myocardial oxygen supply:demand index revisited," Journal of the American Heart Association, vol. 3, no. 1, Article ID e000285, 2014.

[7] D. Baller, H. J. Bretschneider, and G. Hellige, "Validity of myocardial oxygen consumption parameters," Clinical Cardiology, vol. 2, no. 5, pp. 317-327, 1979.

[8] P. Libby, R. O. Bonow, D. L. Mann, and D. P. Zipes, Braunwald's Heart Disease: A Textbook of Cardiovascular Medicine, Elsevier, Amsterdam, Netherlands, 8th edition, 2007.

[9] J. M. Downey and E. S. Kirk, "Inhibition of coronary blood flow by a vascular waterfall mechanism," Circulation Research, vol. 36, no. 6, pp. 753-760, 1975.

[10] J. A. Spaan, N. P. Breuls, and J. D. Laird, "Diastolic-systolic coronary flow differences are caused by intramyocardial pump action in the anesthetized dog," Circulation Research, vol. 49, no. 3, pp. 584-593, 1981.

[11] H. F. Downey, G. J. Crystal, and F. A. Bashour, "Asynchronous transmural perfusion during coronary reactive hyperaemia," Cardiovascular Research, vol. 17, no. 4, pp. 200-206, 1983.

[12] G. D. Buckberg, D. E. Fixler, J. P. Archie, and J. I. E. Hoffman, "Experimental subendocardial ischemia in dogs with normal coronary arteries," Circulation Research, vol. 30, no. 1, pp. $67-81,1972$.

[13] D. Alyono, R. W. Anderson, D. G. Parrish, X. Z. Dai, and R. J. Bache, "Alterations of myocardial blood flow associated with experimental canine left ventricular hypertrophy secondary to valvular aortic stenosis," Circulation Research, vol. 58, no. 1, pp. 47-57, 1986.

[14] G. Buckberg, L. Eber, M. Herman, and R. Gorlin, "Ischemia in aortic stenosis: hemodynamic prediction," The American Journal of Cardiology, vol. 35, no. 6, pp. 778-784, 1975.

[15] K. L. Gould and B. A. Carabello, "Why angina in aortic stenosis with normal coronary arteriograms?" Circulation, vol. 107, no. 25, pp. 3121-3123, 2003.

[16] R. Rubio and R. M. Berne, "Regulation of coronary blood flow," Progress in Cardiovascular Diseases, vol. 18, no. 2, pp. 105-122, 1975.

[17] N. H. Pijls, J. A. Van Son, R. L. Kirkeeide, B. De Bruyne, and K. L. Gould, "Experimental basis of determining maximum coronary, myocardial, and collateral blood flow by pressure measurements for assessing functional stenosis severity before and after pecutaneous transluminal coronary angioplasty," Circulation, vol. 87, no. 4, pp. 1354-1367, 1993.

[18] D. J. Duncker, J. Zhang, and R. J. Bache, "Coronary pressureflow relation in left ventricular hypertrophy. importance of changes in back pressure versus changes in minimum resistance," Circulation Research, vol. 72, no. 3, pp. 579-587, 1993.

[19] D. J. Duncker, J. Zhang, T. J. Pavek, M. J. Crampton, and R. J. Bache, "Effect of exercise on coronary pressure-flow relationship in hypertrophied left ventricle," American Journal of Physiology-Heart and Circulatory Physiology, vol. 269, no. 1, pp. H271-H281, 1995.

[20] D. J. Duncker and R. J. Bache, "Effect of chronotropic and inotropic stimulation on the coronary pressure-flow relation in left ventricular hypertrophy," Basic Research in Cardiology, vol. 92, no. 4, pp. 271-286, 1997.

[21] F. J. Klocke, R. E. Mates, J. M. Canty, and A. K. Ellis, "Coronary pressure-flow relationships. controversial issues and probable implications," Circulation Research, vol. 56, no. 3, pp. 310-323, 1985. 
[22] D. J. Duncker and R. J. Bache, "Regulation of coronary blood flow during exercise," Physiological Reviews, vol. 88, no. 3, pp. 1009-1086, 2008.

[23] S. Roy, T. Hawkins, and J. P. Bourke, "The safety of dipyridamole-thallium imaging in patients with critical aortic valve stenosis and angina," Nuclear Medicine Communications, vol. 19, no. 8, pp. 789-794, 1998.

[24] C. Carpeggiani, D. Neglia, U. Paradossi, L. Pratali, M. Glauber, and A. L'Abbate, "Coronary flow reserve in severe aortic valve stenosis: a positron emission tomography study," Journal of Cardiovascular Medicine, vol. 9, no. 9, pp. 893-898, 2008.

[25] F. S. Liu, S. Y. Wang, Y. C. Shiau, and Y. W. Wu, “The clinical value and safety of ECG-gated dipyridamole myocardial perfusion imaging in patients with aortic stenosis," Scientific Reports, vol. 9, p. 12443, 2019.

[26] I. G. Burwash, M. Lortie, P. Pibarot et al., "Myocardial blood flow in patients with low-flow, low-gradient aortic stenosis: differences between true and pseudo-severe aortic stenosis. Results from the multicentre TOPAS (Truly or pseudo-severe aortic stenosis) study," Heart, vol. 94, no. 12, pp. 1627-1633, 2008.

[27] K. Rajappan, O. E. Rimoldi, D. P. Dutka et al., "Mechanisms of coronary microcirculatory dysfunction in patients with aortic stenosis and angiographically normal coronary arteries," Circulation, vol. 105, no. 4, pp. 470-476, 2002.

[28] A. Nemes, T. Forster, Z. Kovács, A. Thury, I. Ungi, and M. Csanády, "The effect of aortic valve replacement on coronary flow reserve in patients with a normal coronary angiogram," Herz, vol. 27, no. 8, pp. 780-784, 2002.

[29] M. Baroni, S. Maffei, M. Terrazzi, C. Palmieri, F. Paoli, and A. Biagini, "Mechanisms of regional ischaemic changes during dipyridamole echocardiography in patients with severe aortic valve stenosis and normal coronary arteries," Heart, vol. 75, no. 5, pp. 492-497, 1996.

[30] H. V. Huikuri, U. R. Korhonen, M. J. Ikäheimo, J. Heikkilä, and J. T. Takkunen, "Detection of coronary artery disease by thallium imaging using a combined intravenous dipyridamole and isometric handgrip test in patients with aortic valve stenosis," The American Journal of Cardiology, vol. 59, no. 4, pp. 336-340, 1987.

[31] M. O. Demirkol, B. Yaymac1, H. Debeş, Y. Başaran, and F. Turan, "Dipyridamole myocardial perfusion tomography in patients with severe aortic stenosis," Cardiology, vol. 97, no. 1, pp. 37-42, 2002.

[32] A. Nemes, E. Balázs, M. Csanády, and T. Forster, "Long-term prognostic role of coronary flow velocity reserve in patients with aortic valve stenosis-insights from the SZEGED Study," Clinical Physiology and Functional Imaging, vol. 29, no. 6, pp. 447-452, 2009.

[33] S. D. Avakian, M. Grinberg, J. C. Meneguetti, J. A. F. Ramires, and A. d. P. Mansur, "SPECT dipyridamole scintigraphy for detecting coronary artery disease in patients with isolated severe aortic stenosis," International Journal of Cardiology, vol. 81, no. 1, pp. 21-27, 2001.

[34] A. C. Camuglia, J. Syed, P. Garg et al., "Invasively assessed coronary flow dynamics improve following relief of aortic stenosis with transcatheter aortic valve implantation," Journal of the American College of Cardiology, vol. 63, no. 17, pp. 1808-1809, 2014.

[35] J. Vendrik, Y. Ahmad, A. Eftekhari et al., "Long-term effects of transcatheter aortic valve implantation on coronary hemodynamics in patients with concomitant coronary artery disease and severe aortic stenosis," Journal of the American Heart Association, vol. 9, no. 5, Article ID e015133, 2020.

[36] E. M. A. Wiegerinck, T. P. Van De Hoef, M. C. Rolandi et al., "Impact of aortic valve stenosis on coronary hemodynamics and the instantaneous effect of transcatheter aortic valve implantation," Circulation: Cardiovascular Interventions, vol. 8, no. 8, Article ID e002443, 2015.

[37] Y. Ahmad, M. Götberg, C. Cook et al., "Coronary hemodynamics in patients with severe aortic stenosis and coronary artery disease undergoing transcatheter aortic valve replacement," JACC: Cardiovascular Interventions, vol. 11, no. 20, pp. 2019-2031, 2018.

[38] R. Scarsini, G. Pesarini, C. Zivelonghi et al., "Physiologic evaluation of coronary lesions using instantaneous wave-free ratio (iFR) in patients with severe aortic stenosis undergoing transcatheter aortic valve implantation," EuroIntervention, vol. 13, no. 13, pp. 1512-1519, 2018.

[39] G. Di Gioia, M. Pellicano, G. G. Toth et al., "Fractional flow reserve-guided revascularization in patients with aortic stenosis," The American Journal of Cardiology, vol. 117, no. 9, pp. 1511-1515, 2016.

[40] B. E. Stähli, W. Maier, R. Corti, T. F. Lüscher, and L. A. Altwegg, "Fractional flow reserve evaluation in patients considered for transfemoral transcatheter aortic valve implantation: a case series," Cardiol, vol. 123, pp. 234-239, 2013.

[41] A. Stundl, J. Shamekhi, S. Bernhardt et al., "Fractional flow reserve in patients with coronary artery disease undergoing TAVI: a prospective analysis," Clinical Research in Cardiology, vol. 109, no. 6, pp. 746-754, 2019.

[42] M. Lumley, R. Williams, K. N. Asrress et al., "Coronary physiology during exercise and vasodilation in the healthy heart and in severe aortic stenosis," Journal of the American College of Cardiology, vol. 68, no. 7, pp. 688-697, 2016.

[43] C. Burgstahler, M. Kunze, M. P. Gawaz et al., "Adenosine stress first pass perfusion for the detection of coronary artery disease in patients with aortic stenosis: a feasibility study," The International Journal of Cardiovascular Imaging, vol. 24, no. 2, pp. 195-200, 2008.

[44] D. J. R. Hildick-Smith and L. M. Shapiro, "Coronary flow reserve improves after aortic valve replacement for aortic stenosis: an adenosine transthoracic echocardiography study," Journal of the American College of Cardiology, vol. 36, no. 6, pp. 1889-1896, 2000.

[45] M. Mahmod, S. K. Piechnik, E. Levelt et al., “Adenosine stress native $\mathrm{T} 1$ mapping in severe aortic stenosis: evidence for a role of the intravascular compartment on myocardial T1 values," Journal of Cardiovascular Magnetic Resonance, vol. 16, no. 1, p. 92, 2014.

[46] B. Samuels, H. Kiat, J. D. Friedman, and D. S. Berman, "Adenosine pharmacologic stress myocardial perfusion tomographic imaging in patients with significant aortic stenosis," Journal of the American College of Cardiology, vol. 25, no. 1, pp. 99-106, 1995.

[47] A. Gutiérrez-Barrios, S. Gamaza-Chulián, A. Agarrado-Luna et al., "Invasive assessment of coronary flow reserve impairment in severe aortic stenosis and ecochadiographic correlations," International Journal of Cardiology, vol. 236, pp. 370-374, 2017.

[48] M. Stoller, S. Gloekler, R. Zbinden et al., "Left ventricular afterload reduction by transcatheter aortic valve implantation in severe aortic stenosis and its prompt effects on comprehensive coronary haemodynamics," EuroIntervention, vol. 14, no. 2, pp. 166-173, 2018. 
[49] K. Takemoto, K. Hirata, N. Wada et al., "Acceleration time of systolic coronary flow velocity to diagnose coronary stenosis in patients with microvascular dysfunction," Journal of the American Society of Echocardiography, vol. 27, no. 2, pp. 200-207, 2014.

[50] S. Patsilinakos, S. Spanodimos, F. Rontoyanni et al., "Adenosine stress myocardial perfusion tomographic imaging in patients with significant aortic stenosis," Journal of Nuclear Cardiology, vol. 11, no. 1, pp. 20-25, 2004.

[51] D. Stanojevic, P. Gunasekaran, P. Tadros et al., "Intravenous adenosine infusion is safe and well tolerated during coronary fractional flow reserve assessment in elderly patients with severe aortic stenosis," The Journal of Invasive Cardiology, vol. 28, no. 9, pp. 357-361, 2016.

[52] S. P. Patsilinakos, I. P. Antonelis, G. Filippatos et al., "Detection of coronary artery disease in patients with severe aortic stenosis with noninvasive methods," Angiology, vol. 50, no. 4, pp. 309-317, 1999.

[53] F. Yamanaka, K. Shishido, T. Ochiai et al., "Instantaneous wave-free ratio for the assessment of intermediate coronary artery stenosis in patients with severe aortic valve stenosis," JACC: Cardiovascular Interventions, vol. 11, no. 20, pp. 2032-2040, 2018.

[54] J.-H. Ahn, S. M. Kim, S.-J. Park et al., "Coronary microvascular dysfunction as a mechanism of angina in severe AS," Journal of the American College of Cardiology, vol. 67, no. 12, pp. 1412-1422, 2016.

[55] M. Banovic, V.-T. Bosiljka, B. Voin et al., "Prognostic value of coronary flow reserve in asymptomatic moderate or severe aortic stenosis with preserved ejection fraction and nonobstructed coronary arteries," Echocardiography, vol. 31, no. 4, pp. 428-433, 2014.

[56] K. Singh, A. S. Bhalla, M. A. Qutub, K. Carson, and M. Labinaz, "Systematic review and meta-analysis to compare outcomes between intermediate- and high-risk patients undergoing transcatheter aortic valve implantation," European Heart Journal-Quality of Care and Clinical Outcomes, vol. 3, no. 4, pp. 289-295, 2017.

[57] T. Nishi, H. Kitahara, Y. Saito et al., "Invasive assessment of microvascular function in patients with valvular heart disease," Coronary Artery Disease, vol. 29, no. 3, pp. 223-229, 2018.

[58] H. Arashi, J. Yamaguchi, T. Ri et al., "Evaluation of the cut-off value for the instantaneous wave-free ratio of patients with aortic valve stenosis," Cardiovascular Intervention and Therapeutics, vol. 34, no. 3, pp. 269-274, 2019.

[59] N. Hussain, W. Chaudhry, A. W. Ahlberg et al., “An assessment of the safety, hemodynamic response, and diagnostic accuracy of commonly used vasodilator stressors in patients with severe aortic stenosis," Journal of Nuclear Cardiology, vol. 24, no. 4, pp. 1200-1213, 2017.

[60] M. Banovic, B. Iung, V. Brkovic et al., "Silent coronary artery disease in asymptomatic patients with severe aortic stenosis and normal exercise testing," Coronary Artery Disease, vol. 31, no. 2, pp. 166-173, 2020.

[61] P. C. Cremer, S. Khalaf, J. Lou, L. Rodriguez, M. D. Cerqueira, and W. A. Jaber, "Stress positron emission tomography is safe and can guide coronary revascularization in high-risk patients being considered for transcatheter aortic valve replacement," Journal of Nuclear Cardiology, vol. 21, no. 5, pp. 1001-1010, 2014.

[62] W. Aarnoudse, W. F. Fearon, G. Manoharan et al., "Epicardial stenosis severity does not affect minimal microcirculatory resistance," Circulation, vol. 110, no. 15, pp. 2137-2142, 2004.
[63] B.-J. Verhoeff, T. P. van de Hoef, J. A. E. Spaan, J. J. Piek, and M. Siebes, "Minimal effect of collateral flow on coronary microvascular resistance in the presence of intermediate and noncritical coronary stenoses," American Journal of Physiology-Heart and Circulatory Physiology, vol. 303, no. 4, pp. H422-H428, 2012.

[64] S. Fournier, I. Colaiori, G. Di Gioia, T. Mizukami, and B. De Bruyne, "Hyperemic pressure-flow relationship in a human," Journal of the American College of Cardiology, vol. 73, no. 10, pp. 1229-1230, 2019.

[65] S. S. Goel, M. Ige, E. M. Tuzcu et al., "Severe aortic stenosis and coronary artery disease-implications for management in the transcatheter aortic valve replacement era," Journal of the American College of Cardiology, vol. 62, no. 1, pp. 1-10, 2013.

[66] M. Lunardi, R. Scarsini, G. Venturi et al., "Physiological versus angiographic guidance for myocardial revascularization in patients undergoing transcatheter aortic valve implantation," Journal of the American Heart Association, vol. 8, no. 22, Article ID e012618, 2019.

[67] K. L. Gould, "Pressure-flow characteristics of coronary stenoses in unsedated dogs at rest and during coronary vasodilation," Circulation Research, vol. 43, no. 2, pp. 242-253, 1978.

[68] J. M. Zelis, P. A. L. Tonino, and N. P. Johnson, "Why can fractional flow reserve decrease after transcatheter aortic valve implantation?" Journal of the American Heart Association, vol. 9, Article ID e04905, 2020.

[69] R. L. Kirkeeide, K. L. Gould, and L. Parsel, "Assessment of coronary stenoses by myocardial perfusion imaging during pharmacologic coronary vasodilation. VII. validation of coronary flow reserve as a single integrated functional measure of stenosis severity reflecting all its geometric dimensions," Journal of the American College of Cardiology, vol. 7, no. 1, pp. 103-113, 1986.

[70] K. Rajappan, O. E. Rimoldi, P. G. Camici, N. G. Bellenger, D. J. Pennell, and D. J. Sheridan, "Functional changes in coronary microcirculation after valve replacement in patients with aortic stenosis," Circulation, vol. 107, no. 25, pp. 3170-3175, 2003.

[71] G. Pesarini, R. Scarsini, C. Zivelonghi et al., "Functional assessment of coronary artery disease in patients undergoing transcatheter aortic valve implantation: influence of pressure overload on the evaluation of lesions severity," Circulation: Cardiovascular Interventions, vol. 9, no. 11, Article ID e004088, 2016.

[72] N. P. Johnson, J. M. Zelis, P. A. L. Tonino et al., "Pressure gradient vs. flow relationships to characterize the physiology of a severely stenotic aortic valve before and after transcatheter valve implantation," European Heart Journal, vol. 39, no. 28, pp. 2646-2655, 2018.

[73] D.-H. Kang, S.-J. Park, S.-A. Lee et al., "Early surgery or conservative care for asymptomatic aortic stenosis," New England Journal of Medicine, vol. 382, no. 2, pp. 111-119, 2020. 